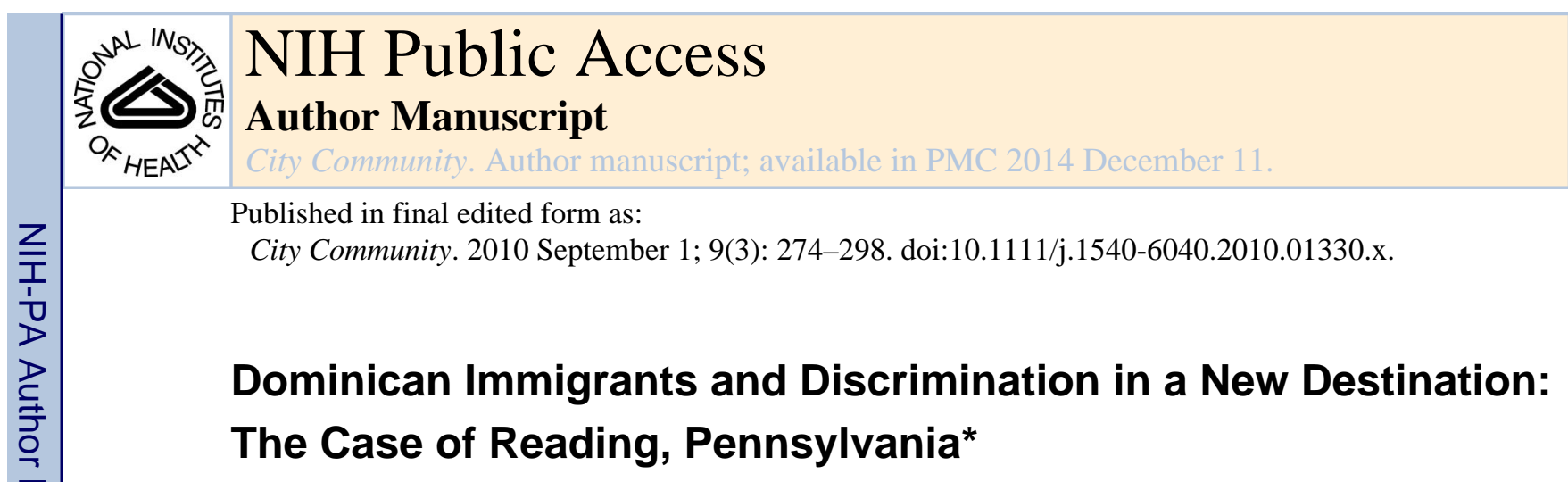

\author{
R.S. Oropesa and \\ Department of Sociology, 201 Oswald Tower, The Pennsylvania State University, University Park, \\ PA 16802 \\ Leif Jensen \\ Department of Agricultural Economics and Rural Sociology, 110-B Armsby, The Pennsylvania \\ State University, University Park, PA 16802
}

\begin{abstract}
The last decade has witnessed the diversification of immigrant destinations in the United States. Although the literature on this phenomenon is burgeoning, research on the experiences of smaller immigrant groups in new destinations is underdeveloped. This is especially the case for those from the Dominican Republic, a group that is expanding beyond the traditional gateway cities of the Northeast. Using a survey of Dominican immigrants in Reading, Pennsylvania, this study has two objectives. The first objective is to describe the prevalence of experiences with institutional and interpersonal discrimination. The second objective is to determine the extent to which these experiences are structured around racial markers (i.e. skin tone), forms of capital, forms of incorporation, and exposure to the U.S. Our results show that a substantial minority of Dominican immigrants claims to have been treated unfairly, primarily because of their "race and ethnicity." In addition, experiences with some types of discrimination are positively associated with skin tone (i.e., darkness) and several factors that are identified in models of assimilation.
\end{abstract}

\title{
Keywords
}

DISCRIMINATION; DOMINICANS; IMMIGRANTS; ASSIMILATION

\begin{abstract}
Since the passage of the Immigration and Nationality Act Amendments in 1965, there have been a series of well-known changes in both the volume and origins of immigration to the United States. The volume of immigration from non-European countries has grown substantially and this has resulted in greater diversity in immigrant origins. The growing diversity in origin countries has been accompanied by the diversification of immigrant destinations (Massey and Capoferro 2008; Singer 2004). Immigrants are increasingly likely to settle in places other than the traditional metropolitan ports-of-entry of the past, including medium and small-sized cities along with non-metropolitan counties (Kandel and Cromartie 2004; Lichter and Johnson 2006). In turn, this is responsible for substantial increases in immigrant populations that have stretched the social and political fabric of many of these new destinations.
\end{abstract}


Migration from the Dominican Republic exemplifies these trends. The number of Dominican immigrants has increased from 12 thousand to 700 thousand since the 1960s, with metropolitan New York and Bergen-Passaic serving as the primary destinations (Portes and Rumbaut 2006). At the same time, Dominican destinations have expanded beyond the traditional gateways. In 1980, over $85 \%$ of Dominican immigrants lived in New York (77\%) and New Jersey (8\%). By 2005, this figure dropped to 67\%, with 54\% in New York (authors'calculations, www.ipums.org).

This changing geography is important for a variety of reasons, including concerns about the reception of immigrants and their prospects for assimilation in new destinations.

Assimilation is problematic when local institutions and local populations are unreceptive to immigrants and engage in various forms of discrimination. Discrimination is especially relevant to Dominicans because they are Spanish speakers with phenotypical characteristics that are associated with African ancestry. Indeed, both classic and modern perspectives on assimilation are pessimistic about the prospects of immigrants from places such as the Dominican Republic who may have difficulty navigating the "black-white" color line due to racial discrimination (Alba and Nee 2003; Portes and Rumbaut 2006).

Although numerous studies have documented the socio-economic disadvantages faced by Dominicans for the nation as a whole (National Research Council 2006; Portes and Rumbaut 2006), there has been less attention to their experiences in new destinations. At risk of overstatement, the emerging literature on new destinations tends to focus disproportionately on Mexican migrants in the South and the Midwest. ${ }^{1}$ Because Hispanic subgroups and locations are not necessarily interchangeable, it is unclear whether findings from these studies are generalizable to Spanish Caribbean groups such as Dominicans in the Northeast. This is especially the case for efforts to understand experiences with discrimination, which is an understudied topic itself. We take a step toward overcoming these limitations with an investigation conducted in Reading, Pennsylvania that accomplishes two objectives. First, we document the prevalence of self-reported experiences with institutional and interpersonal discrimination. Second, we demonstrate how such experiences are structured around racial markers (skin tone) and various indicators of disadvantage that are prominent in models of assimilation.

\section{READING, PA}

Originally planned by the sons of William Penn in the mid-1700s, Reading is now

Pennsylvania's fifth largest city with a population of approximately 80,000 residents located along the Schuylkill River in southeastern Pennsylvania. ${ }^{2}$ Like many places in the region, Reading's growth through the nineteenth century was closely linked to the development of railroads and the transportation of coal to serve various ancillary industries associated with the production of iron, steel, and manufactured goods. The past vitality of the city is demonstrated by its perennial status as one of the 100 largest cities in the U.S. from 1820 to

\footnotetext{
${ }^{1}$ Evidence for this claim can be found in the edited collections by Arreola (2004), Massey (2008), Murphy, Blanchard and Hill (2001), Smith and Furuseth (2006), and Zúñiga and Hernández-León (2005). Exceptions include research on Dominicans' racial identities in Providence, Rhode Island by Bailey (2001) and Itzigsohn, Giorguli, and Vazquez (2005).

${ }^{2}$ Reading is about 60 miles northwest of Philadelphia and 120 miles southwest of New York.
} 
1950. Reading's population first reached 80,000 around 1900 and was over 110,000 by 1950 (see www.census.gov).

The city's population fell from its peak as a result of the decline of manufacturing. Mirroring larger transformations in the national economy with the growth of retail services, the area subsequently became known less for being a manufacturing hub than for having the self-proclaimed title of the "Outlet Capital of the World" (Montgomery 2008). And while the surrounding county also experienced some growth due to the decentralization of jobs, Reading's economic growth is below the national average and its economy has been described as "lackluster" (Brookings Institution 2003). In this vein, it is noteworthy that many of the outlets have closed and the area has abandoned its claim to be a "world capital" (Spatz 2005; Fidler 2006).

Reading's socioeconomic and demographic profile is consistent with this portrait. According to the 2000 census, a relatively high percentage of residents live below the poverty threshold ( $26 \%$ vs. $11 \%$ for the state) and relatively few have a high school degree (62\% vs. $82 \%$ for the state). Reading is also relatively diverse in comparison to the state. About $10 \%$ of the local population is foreign born ( $4 \%$ for the state), $37 \%$ is Hispanic ( $4 \%$ for the state), and $12 \%$ is African American (11\% for the state). This diversity does not extend to neighborhoods, where there is a relatively high level of White-Hispanic residential segregation (www.censusscope.org).

To some extent, these figures reflect the impact of migration from Latin America on the population composition of Reading. ${ }^{3}$ The 2000 Census and the 2005 American Community Survey (ACS) indicate that the area's Hispanic population increased from 30 to 40 thousand during the first half of the decade, a remarkable one-third increase. This change has not been due to the growth of the Puerto Rican population, the earliest and the largest Hispanic group with 21 thousand people in the area. Instead, a substantial share of the growth stems from an influx of Mexican and Dominican migrants, the latter primarily from New York and secondarily from the Dominican Republic. There were about 1,700 Dominicans (90\% foreign born) in the city in 2000 and perhaps 5,700 in $2005 .{ }^{4}$ Dominicans are currently the third largest group in the area, behind Puerto Ricans and Mexicans.

A portrait of Reading would not be complete without understanding the position of Dominican migrants, relative to those born in Puerto Rico and Mexico. Table 1 shows that Dominicans face precarious circumstances with a poverty rate of $63 \%$ and an unemployment rate of $26 \%$. Both of these figures are substantially larger than those for Puerto Rican and Mexican migrants. Moreover, large shares of Dominican migrants are not high school graduates, do not speak English well, and are relatively recent immigrants to the U.S. Thus, the relative position of Dominicans in Reading is consistent with their status as a disadvantaged group nationally (Portes and Rumbaut 2006). Nevertheless, even census

\footnotetext{
${ }^{3}$ According to historical censuses, Reading was overwhelmingly inhabited by Pennsylvania natives in the past, with infusions of immigrants from Germany, Ireland, and England in the mid-1800s and Poland, Czechoslovakia, Italy and Greece by the 1930s. No residents were born in Spanish-speaking countries or had Spanish surnames up to 1930

${ }^{4}$ The 2005 ACS provides information for Berks County, which defines the Reading metro area. We estimate the city's Dominican population on the assumption that the share of the county's Dominican population that lived in Reading in 2005 was the same as in the 2000 Census (.914).
} 
statistics for small groups in new destinations must be interpreted cautiously because of the small samples upon which they are based.

The apparently deleterious circumstances faced by Dominicans invites questions about the source of Reading's appeal. ${ }^{5}$ Interviews with our respondents suggest that migrants to Reading are motivated by economic and quality-of-life considerations. The area is appealing as a place that promises better employment opportunities and a lower cost-of-living with cheaper housing, cheaper utilities, cheaper car expenses, and cheaper insurance than in New York. As for quality-of-life, Reading is touted as a place that is relatively quiet and relatively safe (Kugel 2006). Some also move there to be near family members who came before. At the same time, the aforementioned statistics on the economic situation of Dominicans, a high violent crime rate, and a high property crime rate suggests that reality falls short of the "dream". 6

In sum, Reading represents a useful natural laboratory to study the experiences of Dominicans in a new destination. Reading's immigration and industrial history reflect, in microcosm, that of the industrial Northeast. This includes industrial transformations from heavy manufacturing to services, and a historical legacy of a large native Pennsylvanian population supplemented by successive waves of immigration from northern Europe, southern and eastern Europe, and Latin America. ${ }^{7}$ The latest large group of newcomers to the city, Dominicans, tend to be economically disadvantaged migrants from New York City and elsewhere in the U.S., and from the Dominican Republic itself. Moreover, the city had the third fastest growing Dominican population of any metropolitan area in the country during the 1990s, with an increase of nearly $800 \%$ (see Jensen et al. 2006). Compared to several other new destinations for Dominicans (e.g., Raleigh, NC, Grand Rapids, MI, Charlotte, NC), Reading is also unique in having a large pre-existing Hispanic (chiefly Puerto Rican) population coupled with a non-Hispanic white majority and a relatively small African American population. These different elements draw attention to research questions surrounding the salience of discrimination in the experiences of Dominicans.

\section{DISCRIMINATION AND ASSIMILATION}

There has been no more important issue in American society over the last half century than that of racial discrimination. However, Hispanic immigrants are not prominent in benchmark studies of discrimination (National Research Council 2004) and discrimination is not

\footnotetext{
${ }^{5}$ Special tabulations from the census indicates that the lion's share of Dominican migrants to Reading between 1995-2000 came from the major ports-of-entry to the U.S---the New York metropolitan area and Bergen-Passaic, New Jersey---with substantial numbers also coming directly from the Dominican Republic and Puerto Rico. Conversely, there is no primary destination for Dominicans who leave New York. Besides Reading and some locales in New Jersey, secondary northern destinations include Providence and Boston. Secondary southern destinations include Orlando and Miami/Fort Lauderdale.

${ }^{6}$ According to our calculations from 2006 FBI Uniform Crime Reports for cities with more than 25,000 inhabitants, Reading's violent crime rate (124 per 10,000 population) exceeded that of New York (64) and was fourth highest in the state behind three communities in the Philadelphia area and Harrisburg. Reading's property crime rate (573 per 10,000 population) also exceeded that of New York (188) and was second highest in the state, behind Lancaster (http://www.fbi.gov/ucr/cius2006/data/table_08_pa.html). Obviously, such figures should be interpreted cautiously given variation in crime across neighborhoods within cities.

$7^{7}$ This is epitomized by a prominent mural in the city that shows a white man in $18^{\text {th }}$ century garb (presumably William Penn) exchanging a document with an American Indian against a backdrop of faces, factories, railroad engines, and other symbols of the city. The bottom of the mural shows the larger flag of the United States superimposed above the flags of past and present-day sources of immigrants to the area: Germany, Mexico, Italy, Ireland, Puerto Rico, Sweden, Poland, and Greece. These images rest upon the claim that Reading is "A Culturally Minded Community." Conspicuous for its absence is the flag of the Dominican Republic.
} 
prominent in benchmark studies of Hispanics (National Research Council 2006). These omissions are surprising in light of even classic perspectives on assimilation. Nearly 85 years ago, Park and Burgess (1924: 758) ended their rhapsody with a discordant note that alludes to the specter racial discrimination: “...the ease and rapidity with which aliens, under existing conditions in the United States, have been able to assimilate themselves to the customs and manners of American life have enabled this country to swallow and digest every sort of normal human difference, except the purely external ones, like the color of the skin." Later classic statements are more direct. Gordon (1964: 1) claims in the first line of Assimilation in American Life that assimilation is about "problems of prejudice and discrimination arising out of differences in race, religion, and national background."

Contemporary accounts also draw attention to discrimination in reaction to naïve statements about how the fates of immigrants and their descendents are inexorably tied to the hands of time (Alba and Nee 2003; Portes and Rumbaut 2006). The naïve view is that as immigrants spend time in the host society and learn to play by the "rules of the game," human capital acquisition, cultural adaptation, and intimate contacts with the native-born will ultimately facilitate entry into the middle class. If the promise of upward mobility is unfulfilled in the first generation, it is likely to be realized by subsequent generations.

This description is intuitively appealing, perhaps because it reflects public beliefs about the structure of opportunities in the U.S. and the eventual assimilative trajectory of the descendants of European immigrants who overcame discrimination during the golden age of migration. At the same time, segmented assimilation theory challenges the view that the middle class mainstream is the necessary end-point of assimilation for immigrants and the children of immigrants (Portes and Rumbaut 2006; Portes and Zhou 1993). Some immigrants may follow paths that lead toward the middle-class segment of society, but others follow paths that lead toward relatively insulated communities of co-ethnics, the working class, or an "underclass" formed by American minorities who take an oppositional stance toward mainstream values.

The path taken is a function of several factors, the most important of which are the context of reception and pre-existing capital endowments (Portes and Rumbaut 2006). The context of reception refers to government policies toward immigrants from specific countries, the structure of economic opportunities, and features of pre-existing ethnic communities. For example, assimilation into the middle-class mainstream is facilitated by human and financial capital with relatively few barriers to advancement from discriminatory treatment by the host society. Discriminatory treatment, in turn, stems from the racialization of immigrant groups as undesirable "others" based on their phenotypical characteristics. A racialized group with sufficient resources may react by forming a middle-class ethnic segment or enclave within the larger society. Those with few resources who face discriminatory barriers may assimilate into the working class or develop oppositional outlooks characterized by the rejection of conventional values and pessimism about the prospects for economic advancement. In popular imagery, this is the path taken by some segments of the African American and Puerto Rican populations of inner cities. ${ }^{8}$ 
An additional viewpoint draws attention to the institutional environment. Alba and Nee (2003) argue that assimilation has been facilitated by historic shifts in institutions, conceived in terms of civil rights legislation and the establishment of agencies to monitor organizational compliance with regulations barring discrimination. The institutional environment is important because self-interested actors with different forms of capital must function within the regulatory environment established by the government. While recognizing the existence of discrimination, Alba and Nee argue that institutional changes have raised the costs of discrimination. In so doing, attention to the experience of specific groups must focus on the endowments of capital that immigrants possess. Educational, financial, and cultural resources play a large role in determining how immigrants and their descendents adjust to the host society (see also Nee and Sanders 2001). Because the institutional environment is relatively open, immigrant groups that have greater education and professional backgrounds will have greater opportunities for assimilation into the middle-class.

\section{Discrimination and Race}

In these treatments, race is the proverbial "elephant in the room" because of the power of the black-white racial paradigm in American history. Specifically, the "one-drop rule" as a standard for deciding who is black has been a source of consternation for migrants from the Caribbean with African ancestry who resist racial classification systems that do not embrace national origins as a basis for identification (Landale and Oropesa 2001; Oropesa et al. 2008; Rodríguez 2000). Despite these efforts, most observers of contemporary racial dynamics recognize the persistent power of blackness for social categorization and life experiences. Dark-skinned immigrants from the Caribbean are likely to be treated as blacks because "dark skin is a marker that frequently carries the presumption of underclass stigma" (Jaynes 2004: 106). This is why Alba and Nee (2003:133) qualify their optimistic assessment by noting the rigidity of the color line for immigrants and their descendents with "visible African ancestry." Concurring views can be found in portraits of Hispanics, in general, and Dominicans, in particular (Duany 1998; Grasmuck and Pessar 1996; Rodríguez 2000; Torres-Saillant and Hernández 1998).

At the same time, the literature lacks consensus on the pervasiveness of discrimination in various institutional realms. Heckman (1998: 101) claims that the "entire body" of research in the 1990s showed that racial differences in skills, rather than discrimination, is the major source of racial disparities in employment and wages (also Carniero et al. 2005). The National Research Council suggests that group differences in levels of human capital, as opposed to returns to human capital, account for differences in labor market outcomes of whites and Hispanic immigrants/natives (Duncan et al. 2006). In contrast, some analyses of wage differentials suggest that discriminatory treatment in the labor market is pervasive against blacks and Hispanics as a function of skin tone (Darity, Jr. et al. 2002; Gómez 2000).

\footnotetext{
${ }^{8}$ Although the fortunes of immigrants in smaller and larger places can be affected by the receptivity of native whites, their receptivity is not necessarily uniform (Grey and Woodrick 2005). Some suggest that negative reactions may split along class lines with more favorable reactions by community leaders and the middle class. Ambivalent reactions may be more common among working class residents who have civil relations with individual immigrants while holding negative stereotypes about the groups from which they come (Fennelly 2008). The receptivity of native-born co-ethnics and other racial groups may both facilitate an understanding of differences across places in immigrant adjustment (Marrow 2008).
} 
Audit studies also show that both groups are at a disadvantage in hiring decisions (Fix et al. 1993).

Analyses of lending records and audit studies concur in suggesting that discrimination against both blacks and Hispanics happens in mortgage and real estate markets (Ross and Yinger 2002; Stuart, 2003; Turner et al. 2002; Yinger 1995). Although unequal residential outcomes can occur without discrimination, this may partially explain why Dominicans tend to be less segregated from African Americans than Whites (Freeman, 1999) and live in housing that is of relatively poor quality (Schill et al. 1998).

Studies of the criminal justice system, from street-level police enforcement to criminal sentencing are also informative. African Americans and Hispanics are much more likely than whites to be stopped and searched by police for violent crimes, drug crimes, and property crimes than might be expected on the basis of their arrest rates (Gelman et al. 2007). At the other end of the criminal justice system, blacks and Hispanics are at a disadvantage in criminal courts. In Pennsylvania, Hispanics tend to receive stiffer sentences than whites or blacks, even after controlling for criminal history and type of offense (Steffensmeier and DeMuth 2001).

\section{Perceptions of Discrimination}

Unequal outcomes do not necessarily imply inequity, but unequal outcomes may affect interpretations of experiences or beliefs about the prevalence of discrimination. For our purposes, the best source for insights into the experiences and beliefs of Dominicans is the National Survey of Latinos (NSL, Pew Hispanic Center 2002). ${ }^{9}$ Half of those surveyed describe discrimination as a "major" problem and a third describe it as a "minor" problem in institutional settings such as schools and the workplace. Moreover, 30\% of Dominicans said that they or a close family member/friend experienced some form of discrimination and about $20 \%$ claimed personal knowledge of employment discrimination in the previous five years Thus, a majority feels discrimination is an important public issue and a substantial share has first- or second-hand knowledge of discrimination in institutional settings.

As for interpersonal discrimination, a substantial minority of NSL respondents reports being called names or insulted, being disrespected, and receiving poorer service than others in commercial establishments. Two-thirds of Dominican respondents had never been insulted and $60 \%$ never had the other experiences mentioned above. Yet, these figures also suggest that $40 \%$ claimed to been shown "less respect than other people" and $44 \%$ claimed to receive "poorer service than other people in restaurants or stores" at least once in a while. In short,

\footnotetext{
${ }^{9}$ The vast majority of Dominicans in the NSL were born in the Dominican Republic. Two other sources of information on Hispanics are the 1992-94 Multi-City Study of Urban Inequality (Kluegel and Bobo 2001) and the 1989-90 Latino National Political Survey (LNPS, de la Garza et al. 1992). These studies are of limited relevance for describing current views about discrimination because of their advanced age, the conflation of different Hispanic subgroups, or sampling frames that exclude Dominicans (e.g., the LNPS only includes Mexicans, Puerto Ricans, and Cubans). These studies show that Hispanics feel discrimination is a salient issue even though they may not have personally experienced it, but findings differ on whether views vary across subgroups (Kluegel and Bobo 2001; Falcón 1995).
} 
Previous empirical research provides a limited basis for developing expectations about how perceptions of discrimination are structured, especially in the role of phenotypical characteristics such as skin tone. We hypothesize that self-reported experiences with institutional and interpersonal discrimination are positively associated with skin tone (i.e. darkness). This is consistent with descriptive portraits of Dominicans in the U.S. and the growing literature on the effects of phenotype on various outcomes for Hispanics (Gómez 2000; Murguia and Telles, 1996; Telles and Murguia, 1990; Hunter 2002) and Africandescent peoples (Goldsmith et al. 2007). At the same time, Grasmuck and Pessar (1996: 285 ) imply that self reports may be unrelated to skin tone even though "considerations of race discrimination are important to a full understanding of the obstacles confronting the Dominican population in the US." They suggest that "the dilemma comes when Dominicans with African features or dark skin find themselves identified by many in the United States as Black and are discriminated against on that basis (rather than language, for example) and are not prepared to interpret discrimination on these grounds" (p. 290).

The lack of preparation for interpreting experiences in terms of discrimination may be a function of a learning curve that develops with exposure to the U.S. Portes and Bach (1985) argued that experiences with discrimination accumulate over time and views solidify about its pervasiveness as immigrants learn where their racial or ethnic group fits in the larger system of racial stratification. Exposure to particular settings, English language acquisition, education attainment, and youthfulness undermine idealized images of the U.S. and facilitate interpretations of negative experiences as the product of discrimination against immigrants "living in American society without being part of it" (Portes and Bach 1985: 297; Portes and Rumbaut 2006). Similar thinking undergirds suggestive findings from the NSL that perceptions of institutional discrimination and interpersonal discrimination based on physical appearance are positively associated with education and income. Those with lower education and income tend to identify language barriers as a source of interpersonal discrimination.

These findings are somewhat counterintuitive from the vantage point of classical assimilation theory. The classic view is that exposure to the host society leads to greater integration and discriminatory treatment should fade as immigrants acquire greater education, become more successful, and attain greater cultural competence in terms of their mastery of English. In keeping with this view, Kluegel and Bobo (2001) show that perceptions of discrimination among Hispanics are negatively associated with age and different types of human capital such as English language ability.

\section{Research Objectives}

The foregoing shows that discrimination plays a key role in theories immigrant assimilation. However, many studies take the existence of discrimination for granted, perhaps due to the difficulty of documenting decisions that are hidden from view. It is relatively easier to document beliefs and perceptions, but there is limited empirical research on Dominicans in new destinations. Using a survey of Dominican immigrants in Reading, Pennsylvania, the primary objectives of this study are to document the prevalence of experiences and to demonstrate how experiences with institutional and interpersonal discrimination are 
structured. As for prevalence, both forms of discrimination should be reported by a substantial minority of Dominicans if our results mirror those of the NSL. Moreover, reports of institutional and interpersonal discrimination may be associated with skin tone, and also exposure to the U.S., forms of capital, and modes of incorporation that are emphasized in theories of assimilation. If Portes and Bach (1985) are correct, discrimination should be more evident among those with greater experience in Reading and with greater endowments of capital (e.g., education, language). An alternative point-of-view is that these characteristics reduce the potential for discrimination. 10

It should be noted that our approach to the reception of Dominicans in this new destination has been contextualized in terms of frameworks used to describe "assimilation." This contextualization is risky because some scholars still associate this term, "as a kind of autonomic reflex, with the narrowest understanding of Anglo-conformity or the worst excesses of Americanization campaigns" (Brubaker 2001: 533). Although the "autonomic reflex" serves as a valuable reminder of the limits of assimilation as a normative concept and as an empirically accurate description of outcomes, these concerns have waned with the development of contemporary perspectives that strip assimilation of its normative associations. Contemporary accounts problematize assimilation by drawing attention to processes involved in the adjustment of immigrants and their descendents to the host society (Alba and Nee 2003, Brubaker 2001, Portes and Rumbaut 2006). As noted, experiences with discrimination (or the lack thereof) play a key role in descriptions of these processes.

\section{DATA AND METHODS}

We utilize an ethno-survey conducted in 2004 of 61 residents of Reading, Pennsylvania who were born in the Dominican Republic. Because Dominicans are a rare population in Reading and probability samples of rare populations are difficult to generate using standard sampling procedures, we relied upon several methods to recruit respondents. Some respondents were identified from a mass mailing and canvassing of addresses in areas with large concentrations of Hispanics. This procedure identified some respondents, both directly through the initial mailing and indirectly through referrals from the mailing and street-level contacts with residents. These contacts were initiated in a variety of settings such as restaurants and stores that were patronized by Dominican immigrants. Respondents were administered a computer-assisted personal interview (CAPI), available in both Spanish and English, by bilingual interviewers.

As with most other studies of Dominicans, the utilization of non-probability sampling methods creates some uncertainty about representativeness (e.g. Bailey 2001; Itzigsohn and Dore-Cabral 2000; Itzigsohn et al. 2005; Jensen et al. 2006). A comparison between our data and census data on Dominican immigrants in Reading provides some reassurance that our sample is a reasonable cross-section. ${ }^{11}$ Approximately $51 \%$ of the sample is male, which is

\footnotetext{
${ }^{10}$ Non-significant findings might also be expected from a "perfect market" perspective if: (1) perceived experiences are grounded in reality; (2) markets efficiently allocate individuals to positions based on skill levels; and (3) it is inefficient to discriminate unfairly on the basis of non-productivity related characteristics such as skin tone. Non-significant associations could have numerous other sources as well, including unfair treatment of all members of an immigrant group without regard to personal characteristics. This is one reason why information on the pervasiveness of discrimination is needed.

${ }^{11}$ The following figures differ from those in Table 1 because they are based on persons $18+$.
} 
similar to a census figure of $47 \%$. The typical respondent in Reading has been in the U.S. for about 12.4 years and $36 \%$ are naturalized citizens. Their census counterparts have about 11.9 years in the U.S. and approximately $30 \%$ are citizens. Lastly, $46 \%$ of the respondents have a high school degree or higher, compared to $44 \%$ in the census. Such similarities increase confidence in the results.

The analysis is based on all respondents who were born in the Dominican Republic, with no case attrition due to missing data. Specifically, we employ a Bayesian procedure for the multiple imputation of missing data that models missingness for any particular observation on any particular variable as a function of observed values on other covariates (Rubin 1987; Schafer 1997). In so doing, it produces five imputed datasets that reflect the range of reasonable estimates for each missing observation. These individual datasets are then analyzed and estimates are combined using Rubin's rules to generate correct standard errors.

\section{Measurement}

According to the National Research Council (2004: 39), discrimination refers to unequal treatment based on "inadequately justified factors" that has a disparate impact on a group. The emphasis on inadequate justification and disparate impact implies treatment that violates basic principles of fairness. Consistent with this conceptualization, we focus on institutional and interpersonal discrimination (see also Paradies 2006). Institutional discrimination refers to the actions of organizations and the agents of organizations that are deemed unfair. Interpersonal discrimination refers to such treatment in the context of everyday life. These have been described elsewhere as "daily microstressors" (Harrell 2000) that entail "interpersonal avoidance and distancing in face-to-face interactions" (Lott and Maluso 1995: 3).

\section{Dependent Variables}

The summary measure of institutional discrimination is constructed from a series of commonly-used questions about agents of institutions - employers, real estate brokers, educators, and the police. The respondents were asked whether they had experienced any of the following in Reading, for reasons that are unfair: (1) not been hired for a job; (2) fired or denied a promotion; (3) stopped, searched, questioned, physically threatened, or abused by the police; (4) discouraged by a teacher or advisor from continuing education; (5) prevented from moving into a neighborhood by a landlord/realtor [who refused to sell or rent]; and (6) prohibited from speaking Spanish at work or in school. ${ }^{12}$ The primary indicator of institutional discrimination is a dichotomous measure that takes on a value of one if the respondent reported any of the above, and zero otherwise. Three specific items with sufficient cases for analysis are also examined --- employment, police, and language.

Interpersonal discrimination is assessed from indicators of treatment in "everyday life" in Reading. Respondents indicated how often they are: (1) treated with less courtesy and respect than others; (2) given poorer service in restaurants and stores than other people; (3)

\footnotetext{
${ }^{12}$ No presumption is made about whether any of these situations meet legal tests for discrimination. For example, language restrictions in the workplace may appear arbitrary and unfair to immigrants, but challenges have been unsuccessful in the courts. The results are not sensitive to the inclusion of the language item in the overall index.
} 
called names or insulted; (4) threatened or harassed; (5) treated as if they are not smart; (6) treated as if they are dishonest; (7) treated as if other people are afraid of them; and (8) treated as if others are better than them. The seven response categories for these items range from "almost never" and "about once a year" to "at least once a week" and "almost every day."

Two dichotomous measures are constructed from these items. "Overall interpersonal discrimination" contrasts those who experience any of these microstressers at least once a year (coded as 1) with those who never experience them (coded as 0). "Monthly interpersonal discrimination" contrasts those who experience negative treatment at least once a month (coded as 1) and those who experience negative treatment less frequently (coded as 0).

The wording of the questions used to construct the dependent variables is modeled on previous surveys such as the Detroit Area Study and follows recommendations of the MacArthur Research Network on Socioeconomic Status and Health to describe discrimination as a "generic" phenomenon (www.macses.ucsf.edu). Our goal of determining how immigrants broadly frame their experiences in terms of discrimination is consistent with this recommendation, and is justified by the fact that the reasons for unfair treatment and the agents who are responsible for unfair treatment are often concealed. However, information is available on whether respondents attribute their experiences to race and ethnic discrimination because the survey asked them to indicate the reason(s) for unfair treatment by institutional agents. This is a non-trivial issue because unfair treatment may also be due personal attractiveness, age, class, sexual orientation, and various other factors besides race, language, and national origin. Questions about the reasons for interpersonal discrimination were not asked in the survey.

\section{Independent Variables}

The independent variables include indicators of phenotype, demographic characteristics, forms of capital, forms of incorporation, and exposure to Reading. Phenotypic and demographic characteristics include skin tone, sex (males $=1$, females $=0$ ), and age (in years). Skin tone is measured with respondent ratings using five categories ranging from "very light" (coded as 1) to "very dark brown" (coded as 5).

Several variables describe different forms of capital. Financial capital is reflected in personal income (logged). Human capital is measured with information on educational credentials and English language proficiency. As for education, two dummy variables contrast those who have a high school degree and those who have at least a bachelor's degree with those who do not have a high school degree (the reference). Language skills are reflected in the scores for an additive index constructed from items that used a four-point scale to measure self-reported proficiency in speaking, understanding, writing, and reading English. The index ranges in value from 4 to 16 , with higher scores reflecting greater proficiency.

As used here, the concept of incorporation refers to the terms under which immigrants become part of different systems of the host society. ${ }^{13}$ The economic system includes labor markets and the relationships of individuals to labor markets. The latter is reflected in labor 
force attachment, which is measured in terms of employment status (employed vs. not employed). The political system includes government and the relationships of individuals to government institutions. Those who rely on the government for economic support in the form of public assistance (operationalized here as the receipt of TANF or food stamps) can be considered clients of the State. Citizenship is another indicator of incorporation because it signifies equal membership and political rights in the larger community. As such, it is prized by some for providing protection and access to public benefits (Gilbertson and Singer 2003). Naturalized citizens are contrasted with those who are not citizens.

Exposure-A key variable in studies of assimilation is the amount of time spent in particular settings. Because we are concerned with the treatment that Dominican immigrants have received in Reading, exposure is primarily operationalized as the number of years lived there (logged). Also included are the number of years in the U.S. and the percentage of this total that has been spent in Reading. These measures allow us to explore whether the absolute level of exposure or the relative exposure to particular settings is important. It is possible that the interpretation of experiences in a particular locale may depend on the share of one's life that is spent there relative to other locations, rather than the absolute amount of time. Also, the interrelatedness of these measures requires some discretion in statistical modeling. The percentage of years spent in Reading cannot be included in models with the number of years spent in Reading because of colinearity $(\mathrm{r}=.74)$.

\section{Caveats}

Several methodological issues should be acknowledged. The first concerns the scope conditions of research designs for case studies of specific groups in specific cities (or neighborhoods). All such studies raise questions about the uniqueness of the case and the generalizability of results, oftentimes because distinctiveness is a criterion for selection. Reading was selected primarily because of its high growth rate and its location in the Northeast, but it has other distinguishing features that have already been alluded to. The extent to which these features make the experiences of Dominicans with discrimination in Reading "typical" or "atypical" of their counterparts in other places cannot be known without the accumulation of empirical evidence that does not yet exist. We take an initial step in this direction by comparing some of our results with those of a national survey (see below). Nevertheless, the value of our results do not hinge on the outcome of such a comparison given the nascent state of the literature.

Second, is our use of statistical tests for the analysis of a non-probability sample, given that inferential statistics assume probability sampling. Some methodological flexibility is required here because this is an exploratory study and statistical tests remain useful as

\footnotetext{
${ }^{13}$ The conceptual distinctions between incorporation and assimilation are not always clear. As a practical matter, these terms are often used synonymously with little loss in meaning. In fact, the term "incorporate" in the definition of "assimilate" (Oxford English Dictionary). Some have tried to differentiate these terms. For example, Bean and Stevens (2003: 95) view incorporation as "processes by which new groups establish relationships with host societies." This is said to subsume the concept of assimilation and to allow one to speak of economic incorporation, linguistic incorporation, and marital incorporation. These types of incorporation are simply dimensions of assimilation to others who fail to recognize a difference between these terms. The phrase "form of incorporation" is used here to identify the terms under which individuals are part of larger systems, their relationships to larger systems, and their status within larger systems (e.g., as clients of the state, citizens). In contrast, "forms of capital" is used to describe financial, educational, and linguistic resources that individuals possess.
} 
safeguards against arbitrarily deciding what results to highlight. Additional flexibility is required as well because statistical power is a function of sample size. Due to our small $\mathrm{N}$, we extend the criteria for statistical significance to $p<.10$ to reduce the likelihood of committing a Type II error (failing to reject a false null).

Another set of issues concerns data analysis techniques. We analyze the data with logistic regression, a technique that is appropriate for dichotomous dependent variables. The decision to dichotomize the dependent variables was made after careful consideration of alternative strategies for dealing with the data that tried to capture the number of discriminatory acts or events that occurred over time. An alternative number-based measurement strategy was not pursued because there is no assurance that various items tap separate "events" per se. An individual act can encompass several of these types of experiences or just one of these experiences. If it were not for this ambiguity, a case could otherwise be made for analyzing these data with statistical methods for events. Other analysis options are also limited by the small sample size and skewed distributions. The former limits the utility of a multinomial logistic regression and the latter limits the utility of a more conventional OLS regression approach. Consequently, the dependent variables are examined using logistic regression.

Lastly, a limitation that our study shares with others is that information on the alleged perpetrators is not available. Unfair treatment does not necessarily reflect the actions of the non-Hispanic White majority. Antipathy may characterize relations between Hispanic subgroups (e.g., Puerto Ricans and Dominicans) and other minority groups (see Itzigsohn et al. 2005).

\section{RESULTS}

Descriptive statistics are presented in Table 2. The typical Dominican immigrant is a 40 year-old man or woman whose skin tone might be described as falling between "light brown" and "medium brown" (a value of 2.3 on the scale). In keeping with profiles of Dominicans from national-level datasets, our respondents tend to have low levels of education and low-wage jobs. The majority also do not resort to public assistance for support. Some of these socioeconomic characteristics are undoubtedly influenced by the relatively short period of time that respondents have spent in Reading ( 5 years, with 12 years in the U.S.) and their "moderate" level of English proficiency, as well as the fact that the majority are not naturalized citizens.

\section{Institutional Discrimination}

Table 3 provides information on perceptions of institutional (top panel) and interpersonal discrimination (bottom panel). Here we see that $42 \%$ of the respondents claim to have been treated unfairly by an institution or an institutional agent. This substantial figure primarily reflects experiences with employers, the police, and language. As for employment, about one-fifth of the respondents claim to have been denied a job, denied a promotion, or fired unfairly. Similar percentages are shown for the two other most frequently mentioned responses. 
The overall measure of institutional discrimination and the three most frequently mentioned types of discrimination are analyzed with logistic regression in Table 4. For the overall measure, odds ratios from both bivariate and multivariate models are presented. The bivariate results presented in the first column point to several potentially important associations. Consistent with expectations, the likelihood of perceiving discrimination increases with the darkness of one's skin. Moreover, complaints of discrimination are also more common among younger immigrants and male immigrants, as well as those who are proficient in English and who have spent a relatively greater share of their time in Reading.

The multivariate model shown in the second column is restricted to the significant bivariate predictors. These results demonstrate that inferences about the effects of skin tone and English proficiency are resilient; that is, discriminatory treatment is more likely to be mentioned by darker skinned and English proficient Dominicans even after other covariates are controlled for. In contrast, the odds ratios for sex, age, and share of time spent in the area fail to approach significance. ${ }^{14}$

These findings are not sensitive to alternative model specifications that were explored in the preliminary analysis. For example, because the original survey items refer to having "ever" experienced discrimination in Reading, the multivariate results for other covariates such as English proficiency could potentially reflect the omitted measure of the total amount of time that the respondent has lived in the area. The possibility that time could serve as a source of spuriousness is particularly intriguing given that the correlation between English proficiency and the number of years in Reading is non-trivial (Pearson's $r=.47, \mathrm{p}<.001$ ). Nevertheless, substituting number of years for share of years does not change the results for language or the other covariates, except the negative coefficient for age becomes borderline significant. Additional analyses also reveal that inferences about these variables are not affected by the exclusion of various forms of capital or other covariates such as citizenship.

It should be noted that numerous tests for interaction were performed. The test results were negative, even with a "liberal" significance criterion $(\mathrm{p}<.10)$. The bottom line is that skin tone and English language may lead to experiences that are couched in terms of unfair treatment, but their effects are not conditional on other variables examined herein.

Bivariate regressions for the three most frequently mentioned types of discrimination are presented in the remaining columns. Self-reported experiences with the police mirror those for the overall measure. The likelihood of identifying the police as a source of unfair treatment increases with the darkness of one's skin and men are substantially more likely than women to have negative experiences. The odds of reporting unfair treatment is nearly 15 times greater for men than for women, a reflection of the fact that just one woman in our sample claimed to have been treated badly by the police. When coupled with the negative association for age and the positive association for English language utilization, we can see evidence for the types of experiences that are associated with downward assimilation among

\footnotetext{
${ }^{14}$ The reasons for the insignificance of age, sex, and share of time in Reading in the multivariate model are informative. Sex becomes insignificant because males tend to have darker skin tone and are more proficient in English. Age is borderline significant when exposure is not included and share of time in Reading is insignificant when age and English proficiency are controlled for.
} 
young males. It should be noted that these results are robust in multivariate models (not shown).

Perceptions of employment discrimination are primarily a function of exposure.

Respondents who have been in Reading for longer periods of time are more likely to feel that they have been treated unfairly by employers. Being prevented from communicating in Spanish within a school or work setting is less a function of exposure than age, language proficiency, and citizenship. The fact that this experience is more frequently mentioned by young, English proficient, and naturalized citizens reveals an important irony. Those who are linguistically equipped to navigate successfully around the host society with full rights of citizenship are the most likely to find themselves in settings where the opportunity to communicate in Spanish is restricted.

As noted, these data do not reveal what respondents attribute their treatment to. Additional questions asked of those who reported unfair treatment indicate that the overwhelming majority $(78 \%)$ feels race or ethnicity was the root cause. Just one respondent mentioned income (or class) and no one claimed to have been discriminated against because of gender, age, religion, physical characteristics, and sexual orientation. The remainder chose an unspecified "other" reason.

The correlates of attributing mistreatment to race and ethnicity are similar to those for the overall measure of discrimination. Respondents who feel that they have been mistreated because of their race are more likely than those who do not feel this way to be male $(65 \%$ vs. $44 \%$ ), younger (mean age 33 vs. 44), citizens (55\% vs. 24\%), and proficient in English (11.2 vs. 8.0 on the language index). Additionally, they are more likely to receive public assistance (40\% vs. 24\%) and have spent more time in Reading (5.7 vs. 4.6 years). In short, the interpretation of experiences in terms of race and ethnicity is associated with numerous characteristics.

\section{Interpersonal Discrimination}

Returning to Table 3 allows us to examine the two measures of self-reported experiences with interpersonal discrimination. Here we see that respondents are as likely as not to experience interpersonal discrimination during the course of the year (46\%) and nearly a third $(30 \%)$ experience it at least once a month. The latter figure also indicates that $65 \%(.65$ $=.298 / .459$ ) of those who ever experience such treatment during the course of a year do so at least once a month. The most commonly mentioned slights involve being treated as an inferior and a constellation of complaints characterized in terms of disrespect, poor service, lack of intelligence, fear, and dishonesty. Overt threats and insults are rarely mentioned.

Table 5 presents the bivariate and multivariate odds ratios that summarize the associations between the independent variables and the two dichotomous measures of interpersonal discrimination. The first measure contrasts those who report at least one act and those who do not report any acts of interpersonal discrimination during the course of the year. The second measure contrasts those who report frequent experiences (at least once a month) and those who report infrequent experiences (including none at all). As in the previous table, the multivariate models are limited to those variables that are significant in bivariate analyses. 
The most striking contrast between these results and those for institutional discrimination is that few variables are significant. Besides the positive bivariate association for English proficiency, the only variables to achieve significance are citizenship status and the share of years in the U.S. that have been spent in Reading. Those who have spent a greater share of their time in the area are more likely mention interpersonal discrimination, as are citizens. The odds of reporting negative interpersonal experiences among citizens are about three times that of non-citizens, regardless of model or measure. This may reflect differences in expectations. Citizens may be more likely to expect equal treatment, if for no other reason than the fact that the naturalization process involves political socialization about the equality of citizens.

Before turning to the conclusions, it is worth remembering that our decision to relax the significance criterion for rejecting the null was motivated by statistical power considerations and the desire to reduce the possibility of a Type II error. At the same time, some estimates are of sufficient magnitude to warrant additional investigation, despite the statistical tests. Perhaps the most intriguing non-significant odds ratios are those for education. Their values alone suggest that college graduates are less likely to perceive institutional discrimination and more likely to perceive interpersonal discrimination. This might suggest that education can improve access to opportunities, but educational credentials are not on display in interpersonal interactions that can result in treatment that is inconsistent with expectations.

\section{CONCLUSIONS}

Two current trends in immigration to the United States are the diversification of origin countries and the diversification of destinations beyond traditional gateway cities. The former is potentially important for understanding assimilation because immigrants from different countries have different endowments of human and financial capital that can be mobilized in the course of adjusting to life in the U.S. The latter is important because the fortunes of immigrants are tied to the receptivity of the places in which they live.

Receptivity is reflected in formal discrimination by agents of institutions and informal discrimination by co-residents of an area. Discrimination, however, has received scant empirical attention even though it is prominent in theories of assimilation. This dearth of research is particularly evident for small groups in new destinations.

This study of immigrants from the Dominican Republic in Reading, Pennsylvania has attempted to make inroads into this issue. Dominicans are sociologically compelling from the standpoint of assimilation theory as a group with phenotypic markers of African ancestry and cultural markers of Spanish Caribbean ancestry along with the history of the "color line" in America. Reading is equally compelling as a new destination, for reasons other than its portrayal by the national news media as a haven for those making an escape from New York. The area has one of the fastest-growing Dominican populations in the U.S. and a sizable pre-existing Puerto Rican population. Reading is also no stranger to "big city" economic and social problems.

Our first objective was to provide information on the prevalence of personal experiences with discrimination in Reading. About $42 \%$ of the respondents said that they experienced 
some form of institutional discrimination, with nearly half of those pointing to unfair treatment by employers or the police. Half of the respondents also mentioned negative interpersonal treatment during the past year and a third claimed that this occurred at least once a month in the form of poor service and being treated like an "inferior" who was dishonest, not intelligent, and not worthy of respect.

Some perspective on experiences in Reading can be gained by comparing these figures with benchmarks from the National Survey of Latinos. About $18 \%$ of Dominicans in the NSL and $21 \%$ in our survey claimed some type of employment discrimination. As for interpersonal discrimination, about $60 \%$ of Dominicans in the NSL claimed that they are never treated with less respect or receive poorer service than others and $67 \%$ said they were never insulted or called names. In our survey, $80 \%$ were never shown a lack of respect, $73 \%$ never received poorer service, and $87 \%$ were never insulted. Apparently, Dominicans in Reading are not especially likely to interpret their experiences in terms of institutional discrimination and they may be less likely to report insidious forms of interpersonal discrimination than Dominicans in general.

Similarities and differences in perceived discrimination that are revealed by this comparison potentially raise a host of questions about the importance of place: Does it matter that Dominicans have settled in Reading as opposed to somewhere else? Why does it matter? Why does it not matter? These types of questions cannot be answered here with an individual case study alone, or by comparisons with national surveys that prevent placespecific analyses. Rather, they require multi-site designs that isolate the key features of places that are potentially responsible for differences in experiences while simultaneously ruling out selective migration as a cause of place-related "false positives" (i.e., attributing differences across places to differences in the effects of places). In this regard, none of our respondents claimed that they had moved to Reading because of discriminatory treatment or mistreatment somewhere else.

The second objective of this research was to document the extent to which experiences are structured around various characteristics of respondents. The results suggest that skin color is more important for shaping perceptions of institutional discrimination than for interpersonal discrimination. Those with darker skin are more likely to feel that they have been treated unfairly. The effect of skin tone, however, is not conditional. Tests for interactions between skin tone and all of the other covariates were conducted in the preliminary analysis. No interaction term approached significance.

At the same, there is more to understanding perceptions of discrimination than the color of one's skin. Consistent with Portes and Bach (1985), perceptions are positively associated with indicators of assimilation. Those who are relatively proficient in English are more likely than those who are less proficient to perceive unfair treatment. This important because it is inconsistent with a human capital approach which suggests that English proficiency should reduce discrimination by expanding opportunities. English proficiency may increase the cultural competence of immigrants by making them more aware of differential treatment and better able pick up cues that Spanish monolingual speakers might miss. 
Although the overall institutional discrimination index could not be completely disaggregated into the component items, our analysis suggests that the effect of skin tone on the overall index mirrors experiences with police. Those with darker skin are more likely than those with lighter skin to feel that they have been treated unfairly by police in Reading. Moreover, this sense of unfairness is particularly evident among young men who are proficient in English. Such results direct attention to a negative dynamic between immigrant youth and the police in new destinations, with the caveat that these data cannot examine actual events or address the issue of "probable cause" for treatment received. Regardless, concerns about negative spirals of interaction with agents of institutions that could lead to oppositional ideologies among the disadvantaged are raised by these findings.

Consistent with the argument that exposure to a particular setting fosters experiences and interpretations of experiences that are consistent with unfairness, perceptions of employment discrimination are also likely to increase with the number of years or the share of years spent in Reading. Such findings raise questions about what the nature of those experiences are. Time would have an effect if it increased the duration of exposure to the risk of mistreatment by increasing the total time of employment or the number of jobs held in the area. Both of these aspects of employment might also affect perceptions of mistreatment by increasing their consciousness of civil rights issues and different working conditions.

Being forbidden to use Spanish is also more common among those who speak English and are citizens. Such results may reflect the increased access that the most acculturated and assimilated immigrants have to employment and educational settings in which English is expected as the sole means of communication. ${ }^{15}$ This interpretation would be consistent with the non-trivial, albeit non-significant, odds ratio for education which suggests that the most educated are likely to have experienced restrictions on Spanish use in Reading.

We also filled in the portrait of discrimination by investigating the alleged reasons for unfair treatment, an issue that is important for understanding racialization as a process that is reflected in interpretations of experiences. Dominican immigrants overwhelmingly view their experiences with discrimination in terms of race and ethnicity. There may be class and gender dimensions to discrimination by institutional agents, but these are not mentioned by the immigrants themselves. On the contrary, race and ethnicity are mentioned to the exclusion of other factors among males, those who are relatively young, those who are most incorporated into American society as citizens, recipients of public assistance, and those with the greatest exposure to Reading. Therefore, racialization can be seen as a positive function of exposure, incorporation, and assimilation. Interestingly, interpretations of overall treatment in racial terms was not a function of skin tone.

Support was also generated for the claim that interpersonal discrimination is associated with indicators of exposure and incorporation. In particular, negative interpersonal treatment is more likely among naturalized citizens and those who have spent more time in the area. At the same time, the results for interpersonal discrimination differ in at least one important

${ }^{15}$ Time in Reading is positively associated with speaking English with co-workers and the likelihood of having a U.S.-born supervisor among the currently employed. 
way from the results for institutional discrimination - the trinity of skin tone, sex, and age fail to achieve significance for the former. The different results for skin tone are especially noteworthy, given the uncertainty about whether reports of experiences with discrimination are grounded in reality or simply reflect different ideologies and sensitivities. This issue cannot be directly addressed here, but the non-significance of skin tone for interpersonal discrimination may indicate that darker-skinned individuals are neither especially sensitive nor more inclined to interpret "awkward" encounters negatively.

A remaining question is: What do these results about self-reported experiences with discrimination collectively illustrate about the process of assimilation? Before answering this question, we must reiterate that discrimination is a core concern because it is a mechanism for social exclusion and social closure. As such, it is a cause of "friction" that may slow the pace of assimilation and of blocked opportunities that may divert assimilation away from the middle class (or working class) mainstream, especially for non-white immigrant groups. Moreover, self-reported instances of unfair treatment and the reasons for unfair treatment provide one barometer of assimilation. The extent to which individuals feel that they have been treated unfairly and attribute their unfair treatment to ethno-racial distinctiveness signals the extent to which they feel excluded from the promise of full incorporation into the host society.

With this in mind, the contradictions of assimilation in light of the process of racialization in American society can be clarified. The overwhelming majority of Dominicans who feel that they have been treated unfairly attribute their treatment to their race or ethnicity. Issues of class, gender, or sexual orientation are not pervasive in their accounts. Consistent with this, the likelihood of feeling discriminated against in institutional contexts is generally greater among darker skinned individuals, but this is especially evident in reported dealings with the police. At the same time, linguistic assimilation (English) and political assimilation (citizenship) also appear to foster perceptions of some forms of institutional and interpersonal discrimination. These are skills and statuses that are often acquired with the passage of time and exposure to the host society. Similarly, some evidence also suggests that the most highly educated are likely to perceive negative interpersonal treatment. These findings are ironic because they demonstrate that those individuals who have resources which should facilitate incorporation into the host society are the most likely to indicate that they have experienced obstacles in the form of discrimination. Apparently, assimilation, incorporation, and perceptions of discrimination co-exist.

In pointing to some of the contradictions, these findings may ultimately be relevant to perspectives which emphasize the ways in which experiences in the destination may potentially reinforce a sense of "otherness" that is separate from the mainstream and foster reactions that effectively solidify conceptions of ethnic distinctiveness. Before the implications of discrimination as an impediment to assimilation can be fully articulated, research needs to be expanded in several ways. Knowledge of the experiences of immigrant groups can advance through the accumulation of individual case studies, but multi-group and multi-site investigations that span both new and old destinations are needed. Such studies will need to overcome the methodological challenges of generating representative samples of rare populations, as well as differentiating discrimination as a subjective 
experience from discrimination as an objective fact. In other words, an additional challenge is to determine the extent to which self-reports of discrimination and non-discrimination are valid and reliable indicators of how individuals are actually treated. This must be supplemented with investigations of the extent to which experiences of discrimination stem from the treatment by co-ethnics, other minorities, and the majority population. Overcoming these challenges will greatly expand our understanding of the process of immigrant assimilation and adjustment in new settings.

\section{Acknowledgments}

* Support for this research was provided by the Russell Sage Foundation (project \# 88-04-01) and the Population Research Institute at The Pennsylvania State University, which has core funding from the National Institute of Child Health and Human Development (2 R24 HD041025-06). Able research assistance was provided by Martín Moreno and our team of interviewers: Robin Leon, Nancy Quiñónez, Eva-María Suárez Budenbender, Jason De León, Carlos Nye, Rob Griffin and Amanda Martínez. The authors appreciate the comments of the anonymous reviewers.

\section{REFERENCES}

Alba, R.; Nee, V. Remaking the American Mainstream: Assimilation and Contemporary Immigration. Harvard University Press; Cambridge, MA: 2003.

Arreola, DD. Hispanic Spaces, Latino Places: Community and Cultural Diversity in Contemporary America. University of Texas Press; Austin, TX: 2004.

Bailey B. Dominican-American Ethnic/Racial Identities and United States Social Categories. International Migration Review. 2001; 35(3):677-708.

Bobo, LD.; Massagli, MP. Stereotyping and Urban Inequality. In: O'Connor, A.; Tilly, C.; Bobo, LD., editors. Urban Inequality: Evidence from Four Cities. Russell Sage Foundation; New York: 2001. p. 89-162.

Brookings Institution. A Profile of the Reading Area. Center on Urban and Metropolitan Policy; Washington, D.C.: 2003.

Brubaker R. The Return of Assimilation? Changing Perspectives on Immigration and its Sequels in France, Germany, and the United States. Ethnic and Racial Studies. 2001; 24(4):531-548.

Carniero, P.; Heckman, JJ.; Masterov, DV. Understanding the Sources of Ethnic and Racial Wage Gaps and their Implications for Policy. In: Nielsen, LB.; Nelson, RL., editors. Handbook of Employment Discrimination Research : Rights and Realities. Springer; Dordrecht, The Netherlands: 2005. p. 99-136.

Darity W Jr. Hamilton D, Dietrich J. Passing on Blackness: Latinos, Race, and Earnings in the USA. Applied Economics Letters. 2002; 9(13):847-853.

Duncan, BV.; Hotz, J.; Trejo, SJ. Hispanics in the U.S. Labor Market. In: Tienda, M.; Mitchell, F., editors. Hispanics and the Future of America. The National Academy Press; Washington, D.C.: 2006. p. 228-290.

de la Garza, R.; DeSipio, L.; Garcia, FC.; Garcia, J.; Falcon, A. Latino Voices: Mexican, Puerto Rican, and Cuban Perspectives. Westview Press; Boulder, CO: 1992.

Duany J. Reconstructing Racial Identity: Ethnicity, Color, and Class among Dominicans in the United States and Puerto Rico. Latin American Perspectives. 1998; 25(3):147-172.

Falcón, Angelo. Puerto Ricans and the Politics of Racial Identity. In: Harris, HW.; Blue, HC.; Griffith, E., editors. Racial and Ethnic Identity: Psychological Development and Creative Expression. Routledge; New York: 1995. p. 193-207.

Fennelly, K. Prejudice Toward Immigrants in the Midwest. In: Massey, DS., editor. New Faces in New Places: The Changing Geography of American Immigration. Russell Sage Foundation; New York, NY: 2008. p. 151-178.

Grey, MA.; Woodrick, AC. 'Latinos Have Revitalized Our Community': Mexican Migration and Anglo Responses in Marshalltown, Iowa. In: Zúñiga, V.; Hernández-León, R., editors. New 
Destinations: Mexican Immigration in the US. Russell Sage Foundation; New York: 2005. p. 133-154.

Fidler J. Reading: It's not just Outlet Malls Anymore. The Washington Post. Jul 19.2006

Fix, M.; Galster, GC.; Struyk, RJ. An Overview of Auditing for Discrimination. In: Fix, M.; Struyk, RJ., editors. Clear and Convincing Evidence: Measuring Discrimination in America. The Urban Institute; Washington, D.C.: 1993. p. 1-68.

Freeman L. A Note on the Influence of African Heritage on Segregation: The Case of Dominicans. Urban Affairs Review. 1999; 35(1):137-146.

Gelman A, Fagan J, Kiss A. An Analysis of the NYPD's Stop-and-Frisk Policy in the Context of Claims of Racial Bias. Journal of the American Statistical Association. 2007; 102(479):813-823.

Gilbertson G, Singer A. The Emergence of Protective Citizenship in the USA: Naturalization among Dominican Immigrants in the Post-1996 Welfare Reform Era. Ethnic and Racial Studies. 2003; 26(1):25-51.

Goldsmith AH, Hamilton D, Darity W Jr. From Dark to Light: Skin Color and Wages among AfricanAmericans. Journal of Human Resources. 2007; 42(4):701-738.

Gómez C. The Continual Significance of Skin Color: An Exploratory Analysis of Latinos in the Northeast. Hispanic Journal of Behavioral Science. 2000; 22(1):94-103.

Gordon, MM. Assimilation in American Life. Oxford University Press; New York: 1964.

Grasmuck, S.; Pessar, S. First and Second Generation Settlement of Dominicans in the United States: 1960-1990. In: Pedraza, S.; Rumbaut, R., editors. Origins and Destinies: Immigration, Race and Ethnicity in America. Wadsworth Press; Belmont: 1996. p. 280-292.

Harrell SP. A Multidimensional Conceptualization of Racism-Related Stress: Implications for the Well-Being of People of Color. American Journal of Orthopsychiatry. 2000; 70(1):42-57. [PubMed: 10702849]

Heckman J. Detecting Discrimination. Journal of Economic Perspectives. 1998; 12(2):101-116.

Hunter ML. 'If You're Light You're Alright' Light Skin Color as Social Capital for Women of Color. Gender \& Society. 2002; 16(2):175-193.

Itzigsohn J, Dore-Cabral C. Competing Identities? Race, Ethnicity, and Panethnicity among Dominicans in the United States. Sociological Forum. 2000; 15(2):225-247.

Itzigsohn J, Giorguli-Saucedo S. Incorporation, Transnationalism, and Gender: Immigrant Incorporation and Transnational Participation as Gendered Processes. International Migration Review. 2005; 39(4):895-920.

Itzigsohn J, Giorguli S. Vazquez O. Immigrant Incorporation and Racial Identity: Racial SelfIdentification among Dominican Immigrants. Ethnic and Racial Studies. 2005; 28(1):50-78.

Jaynes, G.; Foner, Nancy; Frederickson, George M. Not Just Black and White: Historical and Contemporary Perspectives on Immigration, Race, and Ethnicity in the United States. Russell Sage Foundation; New York: 2004. Immigration and the Social Construction of Otherness: 'Underclass Stigma and Intergroup Relations; p. 100-116.

Jensen L, Cohen JH, Toribio AJ, DeJong GF, Rodríguez L. Ethnic Identities, Language, and Economic Outcomes among Dominicans in a New Destination. Social Science Quarterly. 2006; 87(5):10881099.

Kandel, W.; Cromartie, J. New Patterns of Hispanic Settlement in Rural America. United States Department of Agriculture; Washington, DC: 2004. Rural Development Research Report Number 99

Kluegel, JR.; Bobo, LD. Perceived Group Discrimination and Policy Attitudes: The Sources and Consequences of the Race and Gender Gaps. In: O'Connor, A.; Tilly, C.; Bobo, LD., editors. Urban Inequality: Evidence from Four Cities. Russell Sage; New York: 2001. p. 163-213.

Kugel S. Leaving New York, with Bodega in Tow. New York Times. Oct 29.2006

Landale NS, Oropesa RS. White, Black, or Puerto Rican? Racial Self-Identification among Mainland and Island Puerto Ricans. Social Forces. 2002; 81(1):231-254.

Lichter DT, Johnson KM. Emerging Rural Settlement Patterns and the Geographic Resdistribution of America's New Immigrants. Rural Sociology. 2006; 71(1):109-31. 
Lott, B.; Maluso, D. Introduction: Framing the Question. In: Lott, B.; Maluso, D., editors. The Social Psychology of Interpersonal Discrimination. The Guilford Press; New York: 1995. p. 1-11.

Marrow, H. Hispanic Immigration, Black Population Size, and Intergroup Relations in Small-Town South. In: Massey, DS., editor. New Faces in New Places: The Changing Geography of American Immigration. Russell Sage Foundation; New York, NY: 2008. p. 211-248.

Massey, DS., editor. New Faces in New Places: The Changing Geography of American Immigration. Russell Sage Foundation; New York, NY: 2008.

Massey, DS.; Capoferro, C. The Geographic Diversification of American Immigration. In: Massey, DS., editor. New Faces in New Places: The Changing Geography of American Immigration. Russell Sage Foundation; New York, NY: 2008. p. 25-50.

Montgomery D. The Engine of Change. The Washington Post. Apr 22.2008

Murguia E, Telles EE. Phenotype and Schooling among Mexican Americans. Sociology of Education. 1996; 69(4):276-289.

Murphy, A.; Blanchard, C.; Hill, JA. Latino Workers in the Contemporary South. University of Georgia Press; Athens, GA: 2001.

National Research Council. Measuring Racial Discrimination. The National Academy Press; Washington, D.C.: 2004.

National Research Council. Multiple Origins, Uncertain Destinies: Hispanics and the American Future. The National Academy Press; Washington, D.C.: 2006.

Nee V, Sanders J. Understanding Immigrant Incorporation: A Forms-of-Capital Model. Ethnic and Racial Studies. 2001; 24(3):386-411.

Park, RE.; Burgess, EW. Introduction to the Science of Sociology. The University of Chicago Press; Chicago: 1924.

Paradies Y. A Systematic Review of Empirical Research on Self-Reported Racism and Health. International Journal of Epidemiology. 2006; 35(4):888-901. [PubMed: 16585055]

Pew Hispanic Center. 2002 National Survey of Latinos. Washington, D.C: 2002.

Portes, A.; Bach, RL. Latin Journey: Cuban and Mexican Immigrants in the United States. University of California Press; Berkeley, CA: 1985.

Portes A, Zhou M. The New Second Generation: Segmented Assimilation and its Variants. The Annals of the American Academy of Political and Social Science. 1993; 530(Nov):74-96.

Portes A. Theoretical Convergencies and Empirical Evidence in the Study of Immigrant Transnationalism. International Migration Review. 2003; 37(3):874-892.

Portes, A.; Rumbaut, R. Immigrant America: A Portrait. Third. University of California Press; Berkeley, CA: 2006.

Rodríguez, CE. Changing Race: Latinos, the Census, and the History of Ethnicity in the United States. New York University Press; New York: 2000.

Ross, S.; Yinger, J. The Color of Credit: Mortgage Discrimination, Research Methodology, and Fair Lending Enforcement. MIT Press; Cambridge, MA: 2002.

Rubin, DB. Multiple Imputation for Nonresponse in Surveys. Wiley; New York: 1987.

Schill MH, Friedman S, Rosenbaum E. The Housing Conditions of Immigrants in New York City. Journal of Housing Research. 1998; 9(2):201-235.

Schafer, JL. Analysis of Incomplete Multivariate Data. Chapman \& Hall; London, UK: 1997.

Singer, A. The Rise of the New Immigrant Gateways. Brookings; Washington, D.C.: 2004.

Smith, H.; Furuseth, OJ. Latinos in the New South: Transformations of Place. Ashgate; Burlington, VT: 2006.

Spatz D. Outlet Capital Slogan on Way Out. The Reading Eagle. Sep 12.2005

Steffensmeier D, DeMuth S. Ethnicity and Judges' Sentencing Decisions: Hispanic-Black-White Comparisons. Criminology. 2001; 39(1):145-178.

Stuart, G. Discriminating Risk: The U.S. Mortgage Lending Industry in the Twentieth Century. Cornell University Press; Ithaca, NY: 2003.

Telles EE, Murguia E. Phenotypic Discrimination and Income Differences among Mexican Americans. Social Science Quarterly. 1990; 71(4):682-696. 
Torres-Saillant, S.; Hernández, R. The Dominican Americans. Greenwood; Westport, CT: 1998.

Turner, MA.; Ross, SL.; Galster, GC.; Yinger, J. Discrimination in Metropolitan Housing Markets. US Department of Housing and Urban Development; Washington, D.C.: 2002. 
Table 1

Descriptive Statistics for the Three Largest Hispanic Migrant Groups in Reading

\begin{tabular}{lccc}
\hline Indicator & Dominican Republic & Puerto Rico & Mexico \\
\hline \% Below Poverty & 63.0 & 33.8 & 26.5 \\
\% Unemployed & 26.3 & 12.7 & 9.2 \\
\% Less than high school degree & 63.2 & 59.7 & 72.9 \\
\% Does not speak English well & 52.8 & 24.5 & 50.4 \\
\% In U.S. 0 -5 years & 33.3 & 27.6 & 24.0 \\
\hline
\end{tabular}

Note: These are based on the authors' calculations for those born in the Dominican Republic, Puerto Rico, and Mexico from the integrated Public Use Microdata Samples of the 2000 Census. The weighted N's are: 1,663 for Dominicans (62, unweighted); 9,509 for Puerto Ricans (385, unweighted); and 3,069 for Mexicans (135, unweighted). Given the size of the unweighted N's, the standard errors of these estimates may be nontrivial. 


\section{Table 2}

\section{Descriptive Statistics (N=61)}

\begin{tabular}{|c|c|}
\hline Mean Skin Tone & 2.3 \\
\hline \multicolumn{2}{|l|}{ Sex } \\
\hline$\%$ Male & 50.8 \\
\hline$\%$ Female & 49.2 \\
\hline Mean Age & 40.5 \\
\hline Mean English Proficiency Index & 9.0 \\
\hline \multicolumn{2}{|l|}{ Education } \\
\hline$\%$ College Graduate & 18.0 \\
\hline$\%$ High School Degree & 27.9 \\
\hline$\%$ Not High School Graduate & 54.1 \\
\hline Mean Personal Income & $16,407.6$ \\
\hline \multicolumn{2}{|l|}{ Employment Status } \\
\hline$\%$ Employed & 66.6 \\
\hline$\%$ Not Employed & 33.4 \\
\hline \multicolumn{2}{|l|}{ Receives any Public Assistance } \\
\hline$\%$ Yes & 29.5 \\
\hline$\%$ No & 70.5 \\
\hline \multicolumn{2}{|l|}{ Citizenship Status } \\
\hline$\%$ U.S. Citizen & 36.1 \\
\hline$\%$ Not U.S. Citizen & 63.9 \\
\hline Mean Years in Reading & 5.0 \\
\hline Mean Years in U.S. & 12.4 \\
\hline Mean Share (\%) of U.S. Years spent in Reading & 49.3 \\
\hline
\end{tabular}

Note: The medians for the interval/ratio variables are as follows: age (41.0), income $(\$ 13,500)$, years in Reading (4.0), years in the U.S. (11.0), share of years (42.1). 


\section{Table 3}

Institutional and Interpersonal Discrimination $(\mathrm{N}=61)$

\begin{tabular}{lr}
\hline & Total \\
\hline Overall Institutional Discrimination & \\
\% Any discrimination & 42.0 \\
- \% Employers & 20.7 \\
- \% Educators & 1.6 \\
- \% Police (stop, searched, questioned, threatened) & 18.7 \\
- \% Landlords or real estate agents & 3.3 \\
- \% Forbidden to speak Spanish at School/Work & 19.7 \\
& \\
Overall Interpersonal Discrimination & \\
\% Interpersonal discrimination at least once per year & 45.9 \\
\% Interpersonal discrimination at least once a month & 29.8 \\
- \% Shown lack of respect & 13.1 \\
- \% Poor service & 14.1 \\
- \% Treated as if not smart & 13.4 \\
- \% Treated as if dishonest & 13.1 \\
- \% Treated as if others afraid & 11.5 \\
- \% Treated as if others are better & 23.3 \\
- \% Insulted & 6.9 \\
- \% Threatened & 2.0 \\
\hline
\end{tabular}


Table 4

Logistic Regression: Overall and Specific Types of Institutional Discrimination $(\mathrm{N}=61)$

\begin{tabular}{|c|c|c|c|c|c|}
\hline & \multicolumn{2}{|c|}{$\underline{\text { Overall Discrimination }}$} & \multirow{2}{*}{$\begin{array}{c}\text { Police } \\
\text { Bivariate } \\
\text { Odds Ratio }\end{array}$} & \multirow{2}{*}{$\begin{array}{c}\text { Employment } \\
\text { Bivariate } \\
\text { Odds Ratio }\end{array}$} & \multirow{2}{*}{$\begin{array}{c}\text { Language } \\
\text { Bivariate } \\
\text { Odds Ratio }\end{array}$} \\
\hline & $\begin{array}{c}\text { Bivariate } \\
\text { Odds Ratio }\end{array}$ & $\begin{array}{l}\text { Multivariate } \\
\text { Odds Ratio }\end{array}$ & & & \\
\hline Skin Tone & $2.08^{*}$ & $2.51^{*}$ & $2.87^{*}$ & 1.17 & .98 \\
\hline \multicolumn{6}{|l|}{ Sex } \\
\hline Male & $2.83^{*}$ & 2.03 & $14.63^{*}$ & 1.28 & .96 \\
\hline Female & 1.0 & 1.0 & 1.0 & 1.0 & 1.0 \\
\hline Mean Age & $.93^{* *}$ & .94 & $.90^{*}$ & 1.01 & $.93^{*}$ \\
\hline English Proficiency Index & $1.37^{* *}$ & $1.31^{*}$ & $1.40^{* *}$ & 1.12 & $1.32^{* *}$ \\
\hline \multicolumn{6}{|l|}{ Education } \\
\hline College Graduate & .32 & & .77 & 1.19 & 1.87 \\
\hline High School Degree & 1.05 & & .46 & 1.34 & .45 \\
\hline Not High School Graduate & 1.0 & & 1.0 & 1.0 & 1.0 \\
\hline \multicolumn{6}{|l|}{ Employment Status } \\
\hline Employed & .88 & & .48 & 1.10 & 1.01 \\
\hline Not Employed & 1.0 & & 1.0 & 1.0 & 1.0 \\
\hline Personal Income (log) & 1.19 & & 1.10 & 1.17 & \\
\hline \multicolumn{6}{|l|}{ Receives any Public Assistance } \\
\hline Yes & 1.81 & & 2.64 & 2.14 & 1.98 \\
\hline No & 1.0 & & 1.0 & 1.0 & 1.0 \\
\hline \multicolumn{6}{|l|}{ Citizenship Status } \\
\hline U.S. Citizen & 2.24 & & 1.78 & 1.22 & $5.00 *$ \\
\hline Not U.S. Citizen & 1.0 & & 1.0 & 1.0 & 1.0 \\
\hline Years in Reading (log) & 1.84 & & 1.77 & $2.71^{+}$ & .32 \\
\hline Years in the U.S. $(\log )$ & .60 & & .64 & .82 & .76 \\
\hline Percentage Years in Reading (log) & $1.92 *$ & 1.42 & 1.56 & $3.34^{*}$ & 1.63 \\
\hline
\end{tabular}


${ }^{*}<<.05$,

* ${ }^{* *}<.01$, 
Table 5

Logistic Regressions: Any and Monthly Interpersonal Discrimination $(\mathrm{N}=61)$

\begin{tabular}{|c|c|c|c|c|}
\hline & \multicolumn{2}{|c|}{ Any Interpersonal } & \multicolumn{2}{|c|}{ Monthly Interpersonal } \\
\hline & $\begin{array}{c}\text { Bivariate } \\
\text { Odds Ratio }\end{array}$ & $\begin{array}{l}\text { Multivariate } \\
\text { Odds Ratio }\end{array}$ & $\begin{array}{c}\text { Bivariate } \\
\text { Odds Ratio }\end{array}$ & $\begin{array}{l}\text { Multivariate } \\
\text { Odds Ratio }\end{array}$ \\
\hline Skin Tone & 1.25 & & .96 & \\
\hline \multicolumn{5}{|l|}{ Sex } \\
\hline Male & .94 & & 1.35 & \\
\hline Female & 1.0 & & 1.0 & \\
\hline Mean Age & .99 & & 1.00 & \\
\hline English Proficiency Index & $1.19^{*}$ & 1.09 & 1.06 & \\
\hline \multicolumn{5}{|l|}{ Education } \\
\hline College Graduate & 2.37 & & 2.52 & \\
\hline High School Degree & .95 & & 1.26 & \\
\hline Not High School Graduate & 1.0 & & 1.0 & \\
\hline \multicolumn{5}{|l|}{ Employment Status } \\
\hline Employed & .69 & & 1.50 & \\
\hline Not Employed & 1.0 & & 1.0 & \\
\hline Personal Income (log) & 1.07 & & 1.15 & \\
\hline \multicolumn{5}{|l|}{ Receives any Public } \\
\hline \multicolumn{5}{|l|}{ Assistance } \\
\hline Yes & .92 & & .87 & \\
\hline No & 1.0 & & 1.0 & \\
\hline \multicolumn{5}{|l|}{ Citizenship Status } \\
\hline U.S. Citizen & $3.12^{*}$ & $2.81^{+}$ & $3.13^{+}$ & $3.39^{*}$ \\
\hline Not U.S. Citizen & 1.0 & 1.0 & 1.0 & 1.0 \\
\hline Years in Reading (log) & 1.08 & & 1.35 & \\
\hline Years in the U.S. $(\log )$ & .72 & & .54 & \\
\hline Percent Years Reading (log) & $1.79^{*}$ & $1.79^{+}$ & $1.79^{+}$ & $1.93^{+}$ \\
\hline
\end{tabular}

$* * \mathrm{p}<.01$,

$* * * \mathrm{p}<.001$

$+\mathrm{p}<.10$

* $<<.05$, 